Article

\title{
Combination Therapy with Aminoglycoside in Bacteremiasdue to ESBL-Producing Enterobacteriaceae in ICU
}

\author{
Lucie Benetazzo ${ }^{1}$, Pierre-Yves Delannoy ${ }^{1}$, Marion Houard ${ }^{2}$, Frederic Wallet ${ }^{3}$, \\ Fabien Lambiotte ${ }^{4}$, Anne Vachée ${ }^{5}$, Christian Batt ${ }^{6}$, Nicolas Van Grunderbeeck ${ }^{7}$, Saad Nseir ${ }^{2}$, \\ Olivier Robineau ${ }^{8}$ and Agnès Meybeck $8, *$ (D)
}

1 Service de Réanimation et Maladies Infectieuses, Centre Hospitalier de Tourcoing, 135 Rue du Président Coty, 59200 Tourcoing, France; lbenetazzo@ch-lens.fr (L.B.); pydelannoy@ch-tourcoing.fr (P.-Y.D.)

2 Service de RéanimationMédicale, CHRU de Lille, 2 Avenue Oscar Lambret, 59000 Lille, France; marion.houard@chru-lille.fr (M.H.); saad.nseir@chru-lille.fr (S.N.)

3 Laboratoire de Microbiologie, CHRU de Lille, 2 Avenue Oscar Lambret, 59000 Lille, France; frederic.wallet@chru-lille.fr

4 Service de Réanimation, Centre Hospitalier de Valenciennes, 114 Avenue Desandrouin, 59300 Valenciennes, France; lambiotte-f@ch-valenciennes.fr

5 Laboratoire de Microbiologie, Centre Hospitalier de Roubaix, 11 Boulevard Lacordaire, 59100 Roubaix, France; anne.vachee@ch-roubaix.fr

6 Service de Réanimation, Centre Hospitalier de Dunkerque, Avenue Louis Herbeaux, 59240 Dunkerque, France; cbatt@ch-dunkerque.fr

7 Service de Réanimation, Centre Hospitalier de Lens, 99 Route de la Bassée, 62300 Lens, France; nvangrunderbeeck@ch-lens.fr

8 Service des Maladies Infectieuses et du Voyageur, Centre Hospitalier de Tourcoing, 135 Rue du Président Coty, 59200 Tourcoing, France; orobineau@ch-tourcoing.fr

* Correspondence: ameybeck@ch-tourcoing.fr; Tel.: +33-3-2069-4848

Received: 27 September 2020; Accepted: 3 November 2020; Published: 4 November 2020

\begin{abstract}
Objectives: Evaluation of the efficacy of empirical aminoglycoside in critically ill patients with bloodstream infections caused by extended-spectrum $\beta$-lactamase producing Enterobacteriaceae (ESBL-E BSI). Methods: Patients treated between 2011 and 2018 for ESBL-E BSI in the ICU of six French hospitals were included in a retrospective observational cohort study. The primary endpoint was mortality on day 30. Results: Among 307 patients, 169 (55\%) were treated with empirical aminoglycoside. Death rate was $40 \%$ (43\% with vs. $39 \%$ without aminoglycoside, $p=$ 0.55). Factors independently associated with death were age $\geq 70$ years (OR: $2.67 ; 95 \%$ CI: $1.09-6.54$, $p=0.03$ ), history of transplantation (OR 5.2; 95\% CI: 1.4-19.35, $p=0.01$ ), hospital acquired infection (OR 8.67; 95\% CI: 1.74-43.08, $p=0.008$ ), vasoactive drugs $>48 \mathrm{~h}$ after BSI onset (OR 3.61; 95\% CI: $1.62-8.02, p=0.001$ ), occurrence of acute respiratory distress syndrome (OR 2.42; 95\% CI: 1.14-5.16, $p=0.02$ ), or acute renal failure (OR 2.49; $95 \%$ CI: 1.14-5.47, $p=0.02$ ). Antibiotherapy appropriateness was more frequent in the aminoglycoside group $(91.7 \%$ vs. $77 \%, p=0.001)$. Rate of renal impairment was similar in both groups ( $21 \%$ vs. $24 \%, p=0.59)$. Conclusions: In intensive care unit (ICU) patients with ESBL-E BSI, empirical treatment with aminoglycoside was frequent. It demonstrated no impact on mortality, despite increasing treatment appropriateness.
\end{abstract}

Keywords: antimicrobialcombination; efficacy of combinations; aminoglycoside; bloodstream infections; extended-spectrum $\beta$-lactamase producing Enterobacteriaceae; critical care; bacteremia 


\section{Introduction}

Bloodstream infections (BSI) caused by extended-spectrum $\beta$-lactamase producing Enterobacteriaceae (ESBL-E) are associated with high rates of treatment failure and mortality, especially when appropriate antimicrobial therapy is delayed [1,2]. Selection of empirical antibiotic treatment is determinant in the case of severe sepsis or septic shock. Standard of care of ESBL-E infections is carbapenem. However, increase of carbapenem-resistant Enterobacteriaceae (CRE) resulting from wide empirical use of carbapenems has focused attention on the promotion of carbapenem sparing strategies [3]. Therapeutic options other than carbapenems such as third generation cephalosporins (3GC) or betalactam/betalactamase inhibitor combinations (BLBLI) could be prescribed in the case of susceptible ESBL-producing Enterobacteriaceae. However, clinical data concerning the efficacy of alternative antibiotics for the treatment of infection due to ESBL-producing Enterobacteriaceae are discordant [4-6]. Combination therapy with a beta-lactam and an aminoglycoside has been proposed as an alternative therapy in clinical situations at high risk of complications such as febrile neutropenia. Aminoglycosides may retain activity even in multidrug-resistant Gram-negative bacteria. Their empirical prescription will broaden the antimicrobial spectrum and reduce the risk of inappropriate therapy. Moreover, synergism between aminoglycosides and specific beta-lactams has been shown in vitro for Gram-negative bacteria. Synergistic bactericidal activity may be of particular interest in the case of severe sepsis or septic shock. Nevertheless, several recent studies have failed to demonstrate a clinical benefit of a beta-lactam and aminoglycoside combination over a single beta-lactam antibiotic [7]. Furthermore, combination therapy was associated with an increased risk of renal failure. However, few data are reported in the literature specifically concerning sepsis or septic shock due to ESBL-E infection, a clinical situation in which prescribing an aminoglycoside could benefit the prognosis. In lightof conflicting data regarding the beneficial effect of combination therapy with aminoglycoside, we conducted a retrospective study to describe antibiotic prescriptions and evaluate the prognostic impact of the initial prescription of aminoglycoside in patients with BSI caused by ESBL-E in ICU.

\section{Patients and Methods}

\subsection{Setting and Study Population}

We conducted a multicenter retrospective cohort study in the ICUs of six hospitals (Dunkerque, Lens, Lille, Roubaix, Tourcoing, and Valenciennes) in the north of France over a period of seven years (1 January 2011 through 1 January 2018). Lille Hospital is an academic hospital. All other hospitals are general hospitals. All consecutive patients treated for ESBL-E BSI during the study period were retrospectively included.

Cases were identified using a laboratory database query completed with ICU clinical databased analysis. Cases were defined as adults with blood culture(s) yielding ESBL-E within $24 \mathrm{~h}$ prior to ICU admission or during the ICU stay. In the case of several positive ESBL-E bacteremias during the same infectious episode, only the first positive blood culture was considered for analysis. Patients who had multiple episodes of ESBL-E BSI were included only once in the analysis, and subsequent episodes were considered recurrences or re-infections.

Enterobacteriaceae identification and in vitro antimicrobial susceptibility testing were performed with a Vitek 2 system (bioMérieux, Marcy l'Etoile, France). ESBL diagnosis and susceptibility testing were carried out according to the European Committee on Antimicrobial Susceptibility Testing (EUCAST) breakpoints [8].

Our study was carried out in accordance with national guidelines concerning an observational study conducted retrospectively on collected data (article R.1121-1-1, Décret no. 2017-884 du 9 mai 2017). The present study obtained ethical approval from the local ethicscommittee ofDron Hospital (comitéd'éthique du Centre Hospitalier Gustave Dron) Ethic code: CNIL 2019-10. 


\subsection{Data Collection and Definitions}

The following data were recorded: demographic characteristics, indication(s) of ICU admission, underlying clinical conditions, immunodeficiency, and severity of illness at admission. The underlying diseases were classified with criteria proposed by McCabe and Jackson [9]. Immunodeficiency was defined as neoplasia, neutropenia (neutrophil count $<0.5 \times 10^{9}$ cells/L), treatment with glucocorticosteroids, and/or other immunosuppressive therapy, AIDS, as defined by the U.S. Centers for Disease Control and Prevention. Severity of illness was assessed by Simplified Acute Physiology Score II (SAPS II) and Sepsis-related Organ Failure Assessment (SOFA) score [10,11]. At the time of BSI diagnosis, we recorded prior antimicrobial therapy within one month before BSI, prior ESBL-E colonization, duration of hospital and ICU stay before BSI, severity of illness, presence of shock, usual biochemical, and hematological tests. Shock was defined by usual criteria [12].

Antimicrobial prescriptions were recorded. Empirical treatment was defined as the prescription of antibiotics before culture results were available; empirical treatment was considered appropriate when the isolated pathogen was susceptible in vitro to at least one of the empirically administered antibiotics according to the EUCAST breakpoints. Timing of empirical treatment was considered adequate when it was started during the first $24 \mathrm{~h}$ after BSI diagnosis. Definitive treatment was defined as start, continuation, or change to an effective antibiotic treatment after the culture result was available, according to the pathogen's susceptibility pattern. De-escalation included switching from combination to monotherapy, or from one beta-lactam to another one with a narrower spectrum and lighter selective pressure according to a six-rank consensual classification of beta-lactams [13]. Combination therapy was only considered if two or three antibiotics active against Enterobacteriaceae were part of the initial empirical treatment. BLBLI combination, 3GC, and carbapenems were administered by continuous infusion after a loading dose or by extended infusions, depending on the stability of the antibiotic drugs after reconstitution.

All patients were follow-up until death or release of ICU. Clinical cure was defined as resolution of clinical signs and symptoms, negative blood cultures, and no requirement for additional antibacterial treatment at the end of treatment. We also assessed the proportion of adequate initial antibiotic treatment, duration of mechanical ventilation, catecholamine infusion, and ICU stay after BSI onset, microbiologic success, and multidrug-resistant bacteria acquisition. Microbiologic success was defined as the eradication of the microorganism in blood cultures at the end of treatment. Documented persistence or recurrence was assessed at the end of follow-up.

\subsection{Statistical Analysis}

Continuous variables were expressed as mean values \pm standard deviation or as median (interquartile range), depending on the normality of their distribution. They were compared using the Student's test or the Mann-Whitney U test, as appropriate. Categorical variables were expressed as percentages and evaluated using the chi-square test and Fisher's test when appropriate. Differences between groups were considered to be significant for variables yielding a $p$ value $\leq 0.05$. To determine the independent effect of the variables on mortality at day 30 , we calculated the corresponding unadjusted and multivariate-adjusted hazard ratios of death using the Cox proportional hazard regression analysis. All covariates with $p<0.2$ in the unadjusted model and use of aminoglycoside and combination therapy were entered into the multivariate model. All statistical analysis were performed using SAS 9.2.

\section{Results}

\subsection{Demographic and Clinical Data}

In Figure 1, the flow chart of the study inclusion process is reported (Figure 1). Of the 334 critically ill patients selected for having ESBL-E BSI during the study period, 27 were excluded from the analysis. In four cases, data were missing with regard to empirical antimicrobial prescriptions. 
In 23 cases, patients received aminoglycosides only as definitive treatment. Among the 307 patients included, 169 were treated with aminoglycoside as the empirical treatment and constituted the group with aminoglycoside; 138 did not received aminoglycoside at any time and constituted the group without aminoglycoside.

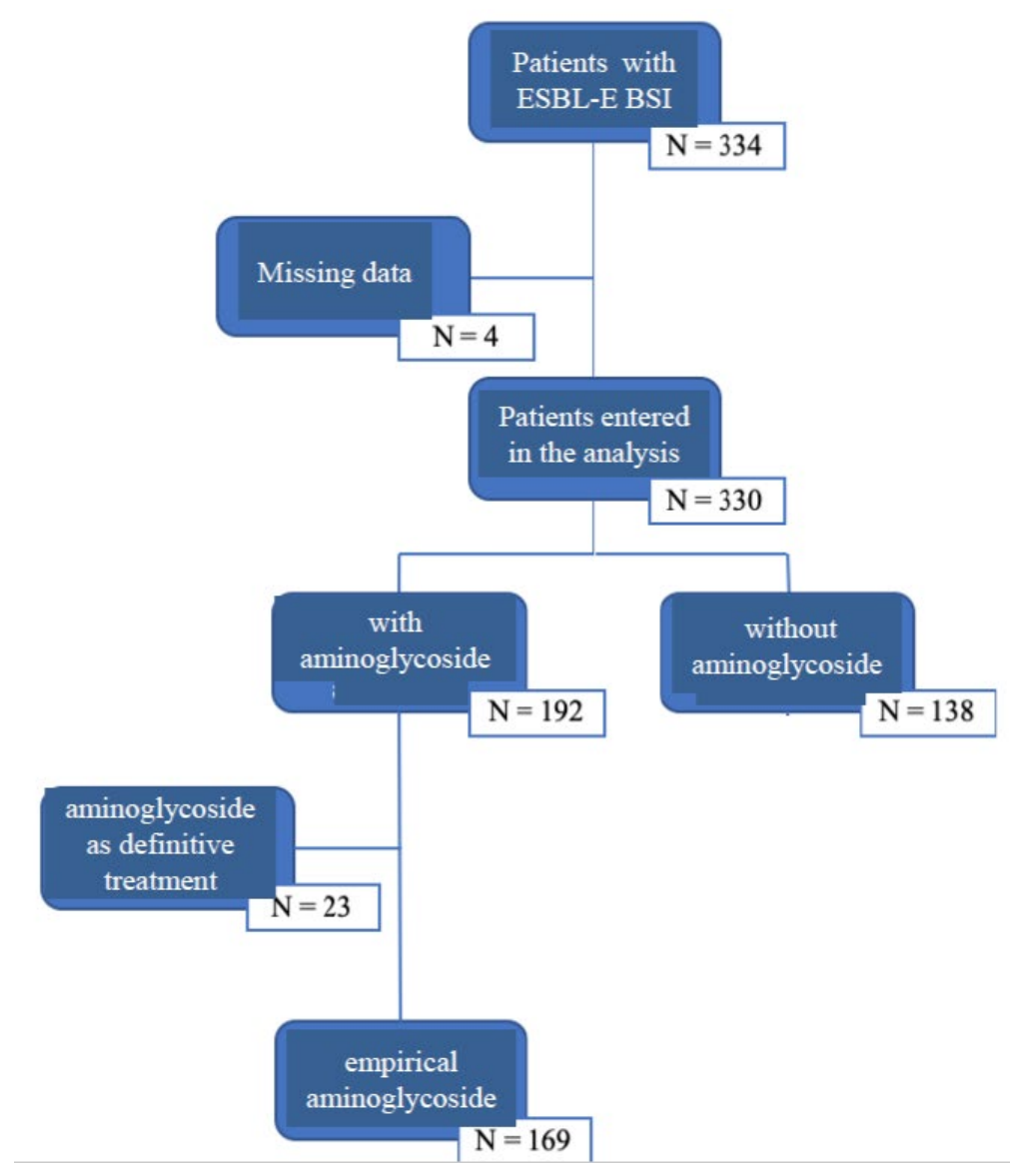

Figure 1. Flow chart of the study inclusion process.

Demographic and clinical characteristics of our patients, depending on aminoglycoside prescription, are shown in Table 1. Our patients were predominantly male (67\%) with a median age of 63 years (IQR, 55-70). The majority of our patients entered ICU for medical admission $(83 \%)$. The median SAPS II value on ICU admission was 50 (IQR, 38-51). Patients treated with aminoglycoside were more frequently receiving immunosuppressive treatment.

ESBL-E BSI was community acquired in $34 \%$ cases. During the two months prior to the occurrence of BSI, 302 patients $(98 \%)$ had received antibiotics. One hundred and seventy two (56\%) patients were colonized with ESBL-E. Upon BSI onset, 164 (53\%) patients exhibited shock: 96 (57\%) in the aminoglycoside group and $59(43 \%)$ in the non-aminoglycoside group $(p=0.02)$. Source of infection was mainly pulmonary in $43 \%$ of cases. Joint and bone infections were few, but more frequent in the group without aminoglycoside ( $3.6 \%$ vs. $0 \%, p=0.02)$. 
Table 1. Demographic and clinical characteristics of our patients depending on aminoglycoside prescription.

\begin{tabular}{|c|c|c|c|}
\hline Characteristics & $\begin{array}{l}\text { Without Aminoglycoside } \\
n=138\end{array}$ & $\begin{array}{c}\text { With Aminoglycoside } \\
n=169\end{array}$ & $p$ \\
\hline Male sex, $n(\%)$ & $95(68.8)$ & $109(64.5)$ & 0.496 \\
\hline Age (years) & $63(54-70)$ & $62(55-70)$ & 0.775 \\
\hline $\mathrm{McCabe}^{3} 2$ & $98(71)$ & $117(69)$ & 0.840 \\
\hline SOFA score & $7(4.25-10.0)$ & $8(5-11)$ & 0.154 \\
\hline \multicolumn{4}{|l|}{ Comorbidity } \\
\hline - Diabetes & $42(30.4)$ & $49(29.2)$ & 0.908 \\
\hline - Renal insufficiency & 16 (11.6) & 18 (10.7) & 0.937 \\
\hline Immunodeficiency & 49 (35.5) & $83(49.1)$ & 0.020 \\
\hline $\begin{array}{l}\text { Immunosuppressive } \\
\text { therapy in the last } 3 \\
\text { months }\end{array}$ & $7(5.1)$ & $25(14.8)$ & 0.010 \\
\hline - Transplantation & $6(4.3)$ & $16(9.5)$ & 0.132 \\
\hline - Solid cancer & $22(15.9)$ & $22(13)$ & 0.573 \\
\hline $\begin{array}{l}\text { - Hematological } \\
\text { malignancy }\end{array}$ & $14(10.1)$ & $20(11.8)$ & 0.775 \\
\hline \multicolumn{4}{|l|}{ Admission } \\
\hline - Medical & $110(79.7)$ & $145(85.8)$ & 0.207 \\
\hline - Scheduled surgical & $2(1.4)$ & $0(0)$ & 0.201 \\
\hline $\begin{array}{l}\text { - Unscheduled } \\
\text { surgical }\end{array}$ & $14(10.1)$ & $20(11.8)$ & 0.775 \\
\hline $\begin{array}{l}\text { Community acquired } \\
\text { infection }\end{array}$ & $42(30.4)$ & $51(30.2)$ & 0.999 \\
\hline \multicolumn{4}{|l|}{ Origin of the infection } \\
\hline - Urinary tract & $13(9.4)$ & $25(14.8)$ & 0.202 \\
\hline $\begin{array}{l}\text { - Intra-abdominal } \\
\text { infection }\end{array}$ & $24(17.4)$ & $29(17.2)$ & 0.999 \\
\hline $\begin{array}{l}\text { - Catheter related } \\
\text { infection }\end{array}$ & $32(23.2)$ & $30(17.8)$ & 0.315 \\
\hline - Respiratory tract & $53(38.4)$ & $75(44,4)$ & 0.313 \\
\hline - Bone infection & $5(3.6)$ & $0(0)$ & 0.018 \\
\hline - other & 10 & 6 & 0.308 \\
\hline \multicolumn{4}{|l|}{ Etiology } \\
\hline - Klebsiella sp. & $87(63)$ & $97(57.4)$ & \\
\hline - Enterobacter sp. & 30 (21.7) & 31 (18.3) & \\
\hline - E.coli & 19 (13.8) & 33 (19.5) & \\
\hline - Other $\S$ & $2(1.5)$ & 8 & \\
\hline polymicrobial infection & $25(1.1)$ & $30(17.8)$ & 0.999 \\
\hline
\end{tabular}
sp. $(n=5)$, Proteus sp. $(n=3)$, Citrobacter sp. $(n=2)$.

\subsection{Microbiological Data}

Overall, Klebsiella pneumoniae (60\%), Enterobacter sp. (20\%), and Escherichia coli (16\%) were the most frequently involved pathogens. Comparison between groups (with aminoglycoside vs. without aminoglycoside) found no difference. Proportion ofESBL-E sensitive to aminoglycosides was 55\%.

\subsection{Empirical and Definitive Antibiotherapy}

Table 2 shows a comparison of antibiotics used in empirical and definitive regimens among patients treated with or without aminoglycoside. Among our patients, 231 (75\%) received a combination therapy, with aminoglycoside in 166 patients (54\%). One hundred and fifty-eight patients (51\%) received a beta-lactam plus an aminoglycoside, five ( $2 \%)$ colistine plus an aminoglycoside, and three (1\%) fluoroquinolone plus an aminoglycoside. A carbapenem was prescribed in 184 patients $(60 \%)$ with the same frequency in both groups ( $64 \%$ with aminoglycoside vs. $57 \%$ without aminoglycoside; $p=0.55)$. 
Table 2. Comparison of antibiotics used in the empirical regimen among patients treated with or without aminoglycoside.

\begin{tabular}{|c|c|c|c|}
\hline \multirow{2}{*}{ Antibiotics } & ithout Aminoglycoside $n=138$ & With Aminoglycoside $n=169$ & \multirow[t]{2}{*}{$p$} \\
\hline & $n(\%)$ & $n(\%)$ & \\
\hline $\begin{array}{l}\text { Non } \\
\text { carbapenem-betalactams }\end{array}$ & $50(36)$ & $58(34)$ & 0.770 \\
\hline amoxicillin-clavulanate & $2(1.4)$ & $0(0)$ & \\
\hline ticarcillin-clavulanate & $1(0.7)$ & $0(0)$ & \\
\hline piperacillin-tazobactam & $29(21)$ & $39(23)$ & \\
\hline cefotaxime/ceftriaxone & $5(3.6)$ & $6(3.6)$ & \\
\hline $\begin{array}{l}\text { - } \text { cefepime } \\
\text { - ceftazidime }\end{array}$ & $\begin{array}{l}4(2.9) \\
5(3.6)\end{array}$ & $\begin{array}{l}3(1.8) \\
8(4.8)\end{array}$ & \\
\hline ceftazidime-avibactam & $1(0.7)$ & $0(0)$ & \\
\hline ceftolozane-tazobactam & $1(0.7)$ & $0(0)$ & \\
\hline - other & $2(1.4)$ & $1(0.6)$ & \\
\hline $\begin{array}{l}\text { Carbapenem antibiotics } \\
\text { - imipenem } \\
\text { - meropenem } \\
\text { - ertapenem } \\
\text { - doripenem }\end{array}$ & $\begin{array}{c}78(56.5) \\
58(42) \\
16(11.6) \\
4(2.9) \\
0(0)\end{array}$ & $\begin{array}{l}106(64) \\
79(47) \\
18(11) \\
8(4.7) \\
1(0.6) \\
\end{array}$ & 0.546 \\
\hline Fluoroquinolone & $35(25.3)$ & $6(3.6)$ & $<0.001$ \\
\hline $\begin{array}{l}- \\
\text { ofloxacin/levofloxacin } \\
\text { - ciprofloxacin }\end{array}$ & $\begin{array}{l}6(4.3) \\
29(21)\end{array}$ & $\begin{array}{l}2(1.2) \\
4(2.4)\end{array}$ & \\
\hline $\begin{array}{l}\text { Anti-cocci Gram positive } \\
\text { - } \quad \text { vancomycin } \\
\text { - } \text { teicoplanin } \\
\text { - } \text { daptomycin }\end{array}$ & $\begin{array}{l}4(2.9) \\
2(1.4) \\
1(0.7) \\
1(0.7)\end{array}$ & $\begin{array}{c}8(4.7) \\
6(3.6) \\
2(1.2) \\
0(0)\end{array}$ & 0.560 \\
\hline $\begin{array}{l}\text { Other } \\
-\quad \text { monobactam }\end{array}$ & $\begin{array}{l}36(26) \\
1(0.7)\end{array}$ & $\begin{array}{c}11(6.5) \\
1(0.6)\end{array}$ & $<0.001$ \\
\hline $\begin{array}{l}- \\
\text { trimethoprim-sulfamethoxazole }\end{array}$ & $2(1.4)$ & $0(0)$ & \\
\hline $\begin{array}{l}\text { - metronidazole } \\
\text { - colistin }\end{array}$ & $\begin{array}{c}2(1.4) \\
31(22.5)\end{array}$ & $\begin{array}{l}2(1.2) \\
8(4.7)\end{array}$ & \\
\hline
\end{tabular}

The proportion of patients who received appropriate initial antibiotic therapy was $79 \%$ (91\% with aminoglycoside vs. $77 \%$ without aminoglycoside, $p=0.001$ ). In 26 patients, the aminoglycoside was the only active antibiotic.

Adjustment of initial empirical antibiotherapy was performed in $39 \%$ of patients treated initially without aminoglycoside and in $49 \%$ of patients treated with aminoglycoside $(p=0.11)$. Switch to an alternative to carbapenem was performed in $4 \%$ of patients in the group without aminoglycoside and $14 \%$ of patients in the group with aminoglycoside $(p=0.075)$.

Among patients treated initially without aminoglycoside, $14 \%$ were transitioned to an aminoglycoside containing regimen.

\subsection{Aminoglycoside Use and Impact}

The most frequently prescribed aminoglycoside was amikacin in $83 \%$ of patients treated with aminoglycoside. Mean duration of aminoglycoside treatment was 1.6 day. Drug monitoring was performed in $39 \%$ of patients treated with aminoglycoside.

Outcome depending on aminoglycoside prescription is summarized in Table 3. Death rate was similar in both groups, respectively $43 \%$ and $39 \%$ with and without empirical aminoglycoside $(p=0.54)$. Eight percent of patients treated empirically with aminoglycoside, and $11 \%$ without aminoglycoside 
experienced a relapse $(p=0.44)$. Persistent colonization with ESBL-Enterobacteriaceae was observed in $28 \%$ of patients treated with empirical aminoglycoside and $30 \%$ of patients treated without empirical aminoglycoside $(p=0.92)$. Acute renal failure occurred in $21 \%$ of patients treated empirically with aminoglycoside and in $23 \%$ of patients treated empirically without aminoglycoside $(p=0.59)$.

Table 3. Outcome according to empirical aminoglycoside prescription.

\begin{tabular}{|c|c|c|c|}
\hline \multirow[t]{2}{*}{ Outcome } & $\begin{array}{l}\text { Without Aminoglycoside } \\
\qquad n=138\end{array}$ & $\begin{array}{l}\text { With Aminoglycoside } \\
\qquad n=169\end{array}$ & \multirow[t]{2}{*}{$p$} \\
\hline & $n(\%)$ & $n(\%)$ & \\
\hline \multicolumn{4}{|l|}{ Complications: } \\
\hline Septic shock & $59(42.8)$ & $96(56.8)$ & 0.020 \\
\hline $\begin{array}{l}\text { Acute respiratory distress } \\
\text { syndrome (ARDS) }\end{array}$ & $27(19.6)$ & $33(19.5)$ & 1.000 \\
\hline Acute renal failure & $33(23.9)$ & $35(20.7)$ & 0.593 \\
\hline $\begin{array}{l}\text { Disseminated intravascular } \\
\text { coagulation (DIC) }\end{array}$ & $15(10.9)$ & $11(6.5)$ & 0.246 \\
\hline Bacteremia relapse & $15(11.1)$ & $13(7.9)$ & 0.448 \\
\hline $\begin{array}{l}\text { Colonization with } \\
\text { multi-drug resistant bacteria } \\
\text { Colonization with }\end{array}$ & $39(29.5)$ & $47(28.3)$ & 0.917 \\
\hline $\begin{array}{l}\text { carbapenem-resistant } \\
\text { enterobacteriaceae (CRE) }\end{array}$ & $4(2.9)$ & $2(1.2)$ & 0.414 \\
\hline fungemia & $3(2.1)$ & $3(1.8)$ & 1.000 \\
\hline Clostridium difficile colitis & $2(1.4)$ & $2(1.2)$ & 1.000 \\
\hline \multicolumn{4}{|l|}{ Evolution: } \\
\hline SOFA day $1>7$ & $62(44.9)$ & $89(53)$ & 0.487 \\
\hline Vasopressors $>48 \mathrm{~h}$ & $31(23)$ & $46(28)$ & 0.24 \\
\hline $\begin{array}{l}\text { Mechanical ventilation at } \\
\text { day } 30\end{array}$ & $22(16)$ & $22(13)$ & 0.55 \\
\hline Mortality at day 30 & $59(42.8)$ & $66(39.3)$ & 0.545 \\
\hline Death in ICU & $63(45.7)$ & $73(43.2)$ & 0.752 \\
\hline - Male sex & $48 \%$ & $42 \%$ & 0.206 \\
\hline - $\quad$ Age $\geq 70$ years & $58 \%$ & $46 \%$ & 0.291 \\
\hline - Immunodepression & $54 \%$ & $58 \%$ & 0.820 \\
\hline - Hospital acquired & $54 \%$ & $47 \%$ & 0.336 \\
\hline $\begin{array}{l}\text { - Non urinary tract } \\
\text { infection }\end{array}$ & $51 \%$ & $44 \%$ & 0.274 \\
\hline$-\quad$ SOFA $\geq 5$ & $48 \%$ & $45 \%$ & 0.699 \\
\hline - $\quad$ McCabe $\geq 2$ & $60 \%$ & $54 \%$ & 0.402 \\
\hline
\end{tabular}

\subsection{Risk Factors for Mortality}

Significant factors associated with death at day 30 in univariate and multivariate analysis are reported in Table 4. The multivariate analysis identified age $\geq 70$ years (OR 2.67, 95\% CI 1.09-6.54, $p=0.03$ ), history of solid organ transplantation (OR 5.2, 95\% CI 1.4-19.35, $p=0.01$ ), nosocomial infection (OR 8.67, 95\% CI 1.74-43.08, $p=0.008)$, need for vasoactive drugs at day 2 after BSI onset (OR 3.61, 95\% CI 1.62-8.02, $p=0.001$ ), acute respiratory distress syndrome (ARDS) (OR 2.42, 95\% CI 1.14-5.16, $p=0.02$ ), or acute renal failure occurrence (OR 2.49,95\% CI 1.14-5.47, $p=0.02)$ as the variables independently associated with mortality. The prescription of empirical aminoglycoside (OR 1.05, 95\% CI 0.54-5.47, $p=0.02$ ) did not appear as an independent factor for mortality at day 30. 
Table 4. Bivariate and multivariate analysis of risk factors associated with 30-day mortality.

\begin{tabular}{|c|c|c|c|c|}
\hline \multirow{2}{*}{ Variables } & \multicolumn{2}{|c|}{ Bivariate Analysis } & \multicolumn{2}{|c|}{ Multivariate Analysis } \\
\hline & OR & $p$ & OR & $p$ \\
\hline Aminoglycoside & $0.84[0.53-1.34]$ & 0.47 & $1.05[0.54-2.06]$ & 0.89 \\
\hline Male sex & $0.91[0.56-1.46]$ & 0.69 & $0.50[0.25-1.01]$ & 0.05 \\
\hline \multicolumn{5}{|l|}{ Age (years) (reference:age } \\
\hline $55 \leq$ Age $<62$ & $1.75[0.90-3.39]$ & 0.10 & $1.64[0.67-4.03]$ & 0.28 \\
\hline $62 \leq$ Age $<70$ & $1.55[0.80-2.97]$ & 0.19 & $1.49[0.60-3.65]$ & 0.39 \\
\hline Age $\geq 70$ & $2.78[1.44-5.37]$ & 0.00 & $2.67[1.09-6.54]$ & 0.03 \\
\hline Medical admission & $0.62[0.33-1.16]$ & 0.13 & $0.72[0.28-1.88]$ & 0.51 \\
\hline Respiratory insufficiency & $0.97[0.57-1.63]$ & 0.90 & & \\
\hline Chronic liver insufficiency & $0.94[0.41-2.16]$ & 0.88 & & \\
\hline Cardiac insufficiency & $2.16[1.07-4.37]$ & 0.03 & $2.16[0.78-5.98]$ & 0.14 \\
\hline Diabetes & $1.04[0.64-1.68]$ & 0.89 & & \\
\hline Solid cancer & $1.27[0.67-2.42]$ & 0.46 & & \\
\hline Transplantation & $3.79[1.52-9.40]$ & 0.004 & $5.20[1.4-19.35]$ & 0.01 \\
\hline \multicolumn{5}{|l|}{ Source (reference:urinary tract) } \\
\hline Respiratory tract & $1.93[0.88-4.23]$ & 0.10 & & \\
\hline Catheter related infection & $0.91[0.37-2.20]$ & 0.83 & & \\
\hline Intra-abdominal infection & $3.1[1.27-7.60]$ & 0.01 & & \\
\hline Other & $2.88[0.93-8.88]$ & 0.07 & & \\
\hline Hospital acquired infection & 3.82 [1.28-11.44] & 0.02 & $\begin{array}{c}8.67 \\
{[1.74-43.08]}\end{array}$ & 0.01 \\
\hline \multicolumn{5}{|l|}{ SOFA (reference: SOFA < 5) } \\
\hline $5 \leq$ SOFA $<7$ & $0.92[0.47-1.79]$ & 0.80 & $0.54[0.21-1.42]$ & 0.21 \\
\hline $7 \leq \mathrm{SOFA}<11$ & $1.15[0.65-2.01]$ & 0.63 & $0.52[0.23-1.18]$ & 0.12 \\
\hline SOFA $\geq 11$ & $2.32[1.20-4.48]$ & 0.01 & $1.69[0.66-4.34]$ & 0.28 \\
\hline \multicolumn{5}{|l|}{$\begin{array}{l}\text { Duration of vasopressors } \\
\text { (reference: }<24 \mathrm{~h} \text { ) }\end{array}$} \\
\hline between 24 and $48 \mathrm{~h}$ & $4.21[2.33-7.58]$ & $<0.001$ & $3.02[1.24-7.31]$ & 0.01 \\
\hline$>48 \mathrm{~h}$ & $4.09[2.30-7.27]$ & $<0.001$ & $3.61[1.62-8.02]$ & 0.002 \\
\hline Polymicrobial infection & $1.25[0.70-2.24]$ & 0.45 & & \\
\hline Active combination therapy & $0.82[0.50-1.37]$ & 0.45 & $0.55[0.28-1.08]$ & 0.08 \\
\hline $\begin{array}{l}\text { Initial appropriate } \\
\text { antibiotherapy }\end{array}$ & 1.16 [0.59-2.29] & 0.67 & & \\
\hline ARDS & $3.23[1.81-5.76]$ & $<0.001$ & $2.42[1.14-5.16]$ & 0.02 \\
\hline Acute renal failure & $4.87[2.72-8.72]$ & $<0.001$ & $2.49[1.14-5.47]$ & 0.02 \\
\hline
\end{tabular}

\section{Discussion}

Our study confirmed the high mortality associated with ESBL-E BSI in critically ill patients. In our cohort, prescription of aminoglycoside was frequent, led to a higher proportion of appropriate initial treatment, and appeared safe. However, empirical use of aminoglycoside was not associated with a reduction of mortality.

In our cohort of critically ill patients suffering from ESBL-E BSI, the 30 day mortality rate was $40 \%$. This rate was logically significantly higher than those observed in the previously published studies conducted both on patients in the medicine ward and in ICU [2,14]. However, Russo et al. analyzed the outcome of 354 patients suffering from ESBL-E BSI who developed severe sepsis or septic shock, and reported a similar mortality rate of $44 \%$ [15]. In a multicenter study conducted in ICU, ESBL-E infections were associated with a 1.8-fold increase in the overall hazard of dying in the ICU [16].

The high mortality associated with ESBL-E BSI in critically ill patients justified studies designed to identify prognosis factors and to improve their management. Factors associated with mortality in our cohort were age $\geq 70$ years, history of solid organ transplantation, nosocomial infection, the need for vasoactive drugs at day 2 after BSI onset, and acute respiratory distress syndrome, or acute renal failure occurrence. Similarly, Russo et al. identified as factors associated with death in the case of severe sepsis or septic shock due to ESBL-E BSI, the severity of comorbidities and of initial clinical conditions (expressed by age, McCabe classification, Charlson Comorbidity Index, and Pitt bacteremia score) and the worsening of clinical conditions (expressed by the need of escalation of initial antibiotic therapy) [15]. In their study, the abdominal source of infection was also associated with an unfavorable 
outcome at 30 days. In contrast, the use of a quinolone in definitive therapy was associated with 30-day survival and found no association between a particular initial therapy and a reduction of mortality.

Our study failed to demonstrate a favorable prognostic impact of initial aminoglycoside prescription in patients with BSI caused by ESBL-E in ICU. In our cohort, prescription of aminoglycoside was frequent. Almost half of our patients received aminoglycoside as part of the initial therapy, mostly as a combination therapy. This observation is concordant with the results of a French survey focused on the early management of BSI. Empirical combination therapy was used in 57\% patients with severe sepsis or septic shock, frequently including an aminoglycoside [17]. In a large international retrospective cohort study including 4662 patients with septic shock, one third of the patients received initial combination therapy with an aminoglycoside in more than $10 \%$ of cases [18].

In this last study, the authors demonstrated a therapeutic benefit of early combination therapy comprising at least two antibiotics of different mechanisms with in vitro activity for the isolated pathogen in patients with bacterial septic shock. The arguments for prescribing a combination therapy with aminoglycoside in critically ill patients with ESBL-E BSI are synergistic bactericidal activity and antimicrobial spectrum broadening. The retrospective design of our study prevents any strong conclusion concerning the reason for the ICU doctors for prescribing aminoglycoside. We can only assume the rationale for their prescription by analyzing patients treated with or without aminoglycoside. In our cohort, prescription of initial antibiotic combination with aminoglycoside seemed mainly motivated by its synergistic bactericidal activity. Indeed, aminoglycoside prescription was more frequent in the case of septic shock and was not associated with carbapenem sparing, since the proportion of our patients receiving carbapenem as the initial therapy was similar with or without empirical aminoglycoside. In our study, neither prescription of aminoglycoside nor prescription of an initial active bitherapy were associated with reduced mortality. Numerous studies have compared aminoglycoside and beta-lactam combination with betalactam monotherapy $[7,19,20]$. Most studies did not find any survival benefit of combination therapy. The heterogeneity of population included in these studies prevented any strong conclusion [21]. Few studies focused on critically ill patients. In this particular context, combination therapy might improve the clinical prognosis of bacteremia. Delannoy PY et al. found a survival benefit of aminoglycoside combination therapy over betalactam monotherapy in the case of ICU-acquired BSI [22]. Similarly, Kumar et al. demonstrated a clinical benefit of early combination therapy in the case of septic shock [18]. None of these studies included only resistant bacteria. In our cohort, prescription of early combination therapy with an aminoglycoside resulted in aminoglycoside effective monotherapy in $16 \%$ of cases, preventing the synergistic bactericidal activity in those cases. In a multinational retrospective cohort study of patients with ESBL-E BSI, Palacios-Baena et al. did not find different outcomes in patients receiving empiric active monotherapy with aminoglycoside compared with carbapenem [23].

In our cohort, antimicrobial spectrum broadening induced by aminoglycoside prescription led to a significantly higher proportion of appropriate initial antibiotherapy in patients receiving aminoglycoside. Appropriate therapy for sepsis has been shown to improve survival, especially in critically ill patients [24-26]. In a study including patients with ESBL-E BSI, Tumbarrelo et al. identified the absence of adequate antimicrobial therapy within the first $72 \mathrm{~h}$ of infection as an independent predictor of mortality [2]. The INCREMENT-ESBL predictive score validated to evaluate the risk of death in patients with ESBL-E BSI includes appropriate early targeted therapy [27]. In our cohort of critically ill patients suffering from ESBL-BSI, appropriate initial antibiotherapy was not associated with mortality reduction. Similarly, Russo et al. found no impact on mortality of adequate initial therapy in their series of severe sepsis and septic shock associated with ESBL-E BSI [15]. They advocated that, in the case of septic shock, appropriate antimicrobial treatment failed to stop the lethal cascade of events already triggered. Rapid diagnosis of sepsis and the quality of supportive care through implementation of sepsis guidelines are key to prognosis [28].

The potential clinical benefit of aminoglycoside combination therapy is counterbalanced by aminoglycoside side effects, especially nephrotoxicity. Aminoglycoside nephrotoxicity has been shown 
to be influenced by multiple factors including longer duration of therapy, preexisting renal or liver disease, shock, older age, and location in intensive care [29]. In our cohort of critically ill patients with ESBL-E BSI, we found no deleterious impact of aminoglycoside prescription on acute renal failure occurrence and need for hemodialysis. Duration of aminoglycoside use was short, with a mean duration of treatment of 1.6 day. Almost two-thirds of our patients received only a single dose of aminoglycoside. Guidelines to use a short course of once daily high dosing of aminoglycoside are quite recent [30], but are widely applied by French physicians [31]. Few studies have analyzed nephrotoxicity of empirical antibiotic therapy including a short-course of aminoglycoside. Two retrospective studies found no association between exposure to aminoglycosides and acute renal failure [32,33]. One prospective study conducted in an ICU found an increased incidence of acute renal failure in patients treated with a short-course of aminoglycoside therapy as part of empirical combination therapy in patients with severe sepsis and septic shock [34]. Discordant results concerning nephrotoxicity and inconsistent prognosis impact of initial aminoglycoside therapy in critically ill patients are in contrast with their broad prescription, calling for more robust studies including randomized clinical trials. Critically ill patients with sepsis, potentially caused by Gram-negative bacteria could be included. Randomization should be stratified according to the risk of infection with ESBL-E.

Our study has several limitations. Asour sample was relatively small, a type II error is possible and studies with larger study population might demonstrate additional differences.

We conducted a retrospective multicentric observational study. Due to the retrospective nature of our study, patients receiving combination aminoglycoside therapy may differ in some systematic way beyond the direct effects of the treatment strategy. However, multivariateanalysis allowed for adjusting for confounding variables. Finally, underdosing of aminoglycosides may also have contributed to the absence of their clinical benefit.In our cohort, therapeutic drug monitoring of aminoglycosides was performed in less than half of the patients. Several previous studies conducted in critically ill patients have shown that evena high dose regimen of aminoglycosides led to pharmacodynamic target achievement in less than two thirds of the patients [35,36]. Early achievement of optimal aminoglycoside concentration was associated with better clinical and microbiological responses [36]. Future prospective studies should use high doses of amioglycosides and drug monitoring to confirm achievement of adequate peak concentrations.

\section{Conclusions}

In our cohort of critically ill patients with ESBL-E BSI, prescription of initial combination therapy with aminoglycoside was frequent. However, its benefit was not clearly demonstrated. Aminoglycoside prescription increased the proportion of appropriate empirical therapy, but was not associated with a reduction inmortality. Prospective studies are needed to better determine prognosis impact of initial aminoglycoside therapy in critically ill patients with suspected ESBL-E BSI. They should target a high-risk population as identified in our study, particularly immunodepressed patients and patients suffering from hospital acquired infection.

Author Contributions: Conceptualization: L.B., P.-Y.D., O.R. and A.M.; Methodology: P.-Y.D., O.R. and A.M.; Software: L.B., O.R.; Validation: L.B., M.H., F.W., F.L., A.V., C.B., N.V.G. and S.N.; Formal Analysis: L.B., P.-Y.D., M.H., O.R. and A.M.; Investigation: M.H., F.W., F.L., A.V., C.B. and N.V.G.; Resources: O.R.; Data Curation: O.R. and A.M.; Writing-Original Draft Preparation: L.B., P.-Y.D.; Writing-Review and Editing: All authors; Supervision: A.M.; Visualization: All authors; Project Administration: O.R. All authors have read and agreed to the published version of the manuscript.

Funding: This research received no external funding.

Conflicts of Interest: The authors declare no conflict of interest. 


\section{References}

1. Rodríguez-Baño, J.; Navarro, M.D.; Romero, L.; Muniain, M.A.; de Cueto, M.; Ríos, M.J.; Hernandez, J.R.; Pascual, A. Bacteremia due to extended-spectrum beta-lactamase-producing Escherichia coli in the CTX-M era: A new clinical challenge. Clin. Infect. Dis. 2006, 43, 1407-1414. [CrossRef] [PubMed]

2. Tumbarello, M.; Sanguinetti, M.; Montuori, E.; Trecarichi, E.M.; Posteraro, B.; Fiori, B.; Citton, R.; D’Inzeo, T.; Fadda, G.; Cauda, R.; et al. Predictors of mortality in patients with bloodstream infections caused by extended-spectrum beta-lactamase-producing Enterobacteriaceae: Importance of inadequate initial antimicrobial treatment. Antimicrob. Agents Chemother. 2007, 51, 1987-1994. [CrossRef] [PubMed]

3. Nordmann, P.; Naas, T.; Poirel, L. Global spread of carbapenemase-producing enterobacteriaceae. Emerg. Infect. Dis. 2011, 17, 1791-1798. [CrossRef] [PubMed]

4. Rodriguez-Bano, J.; Navarro, M.D.; Retamar, P.; Picon, E.; Pascual, A.; The Extended-Spectrum Beta-Lactamases-Red Espanola de InvestigacionenPatologiaInfecciosa/Grupo de Estudio de InfeccionHospitalaria Group. ß-Lactam/B-Lactam inhibitor combinations for the treatment of bacteremia due to extended-spectrum B-lactamase-producing Escherichia coli: A post hoc analysis of prospective cohorts. Clin. Infect. Dis. 2012, 54, 167-174. [CrossRef] [PubMed]

5. Vardakas, K.Z.; Tansarli, G.S.; Rafailidis, P.I.; Falagas, M.E. Carbapenems versus alternative antibiotics for the treatment of bacteraemia due to enterobacteriaceae producing extended-spectrum $B$-lactamases: A systematic review and meta-analysis. J. Antimicrob. Chemother. 2012, 67, 2793-2803. [CrossRef]

6. Harris, P.N.A.; Tambyah, P.A.; Lye, D.C.; Mo, Y.; Lee, T.H.; Yilmaz, M.; Alenazi, T.H.; Arabi, Y.; Falcone, M.; Bassetti, M. Effect of piperacillin-tazobactam vs meropenem on 30-day mortality for patients with E. Coli or Klebsiella pneumoniae bloodstream infection and ceftriaxone resistance: A randomized clinical trial. JAMA 2018, 320, 984-989. [CrossRef]

7. Paul, M.; Lador, A.; Grozinsky-Glasberg, S.; Leibovici, L. Beta lactam antibiotic monotherapy versus beta lactam-aminoglycoside antibiotic combination therapy for sepsis. Cochrane Database Syst. Rev. 2014, 2014, CD003344. [CrossRef] [PubMed]

8. European Committee on Antimicrobial Susceptibility Testing (EUCAST 2012). Breakpoint Tables for Interpretation of MICs and Zone Diameters. Version 2.0. Available online: http://www.eucast.org/ fileadmin/src/media/PDFs/EUCAST-files/Breakpoint-tables/Breakpoint-table-v-2.0-120221.pdf (accessed on 1 August 2020).

9. McCabe, W.R.; Jackson, C.G. Gram-negative bacteremia: Etiology and ecology. Arch. Intern. Med. 1962, 110, 847-855. [CrossRef]

10. Le Gall, J.R.; Lemeshow, S.; Saulnier, F. A new simplified acute physiology score (SAPS II) based on a European/North American multicenter study. JAMA 1993, 270, 2957-2963. [CrossRef]

11. Vincent, J.L.; Moreno, R.; Takala, J.; Willatts, S.; De Mendonça, A.; Bruining, H.; Reinhart, C.K.; Suter, P.M.; Thijs, L.G. The SOFA (Sepsis-related Organ Failure Assessment) score to describe organ dysfonction/failure. Intensive Care Med. 1996, 22, 707-710. [CrossRef] [PubMed]

12. Bone, R.C.; Fischer, C.J.; Clemmer, T.P.; Slotman, G.J.; Metz, C.A.; Balk, R.A. The methylprednisolone severe sepsis study group. Sepsis syndrome: A valid clinical entity. Crit. Care Med. 1989, 17, 389-393. [CrossRef]

13. Weiss, E.; Zahar, J.R.; Lesprit, P.; Ruppe, E.; Leone, M.; Chastre, J.; Lucet, J.C.; Paugam-Burtz, C.; Brun-Buisson, C.; Timsit, J.F.; et al. Elaboration of a consensual definition of de-escalation allowing a ranking of ß-lactams. Clin. Microbiol. Infect. 2015, 21, 649.e1-649.e10.

14. Denis, B.; Lafaurie, M.; Donay, J.L.; Fontaine, J.P.; Oksenhendler, E.; Raffoux, E.; Hennequin, C.; Allez, M.; Socie, G.; Maziers, N.; et al. Prevalence, risk factors, and impact on clinical outcome of extended-spectrum beta-lactamase-producing Escherichia coli bacteraemia: A five-year study. Int. J. Infect. Dis. 2015, 39, 1-6. [CrossRef]

15. Russo, A.; Falcone, M.; Gutierrez-Gutierrez, B.; Calbo, E.; Almirante, B.; Viale, P.L.; Oliver, A.; Ruiz-Garbajosa, P.; Gasch, O.; Gozalo, M.; et al. Predictors of outcome in patients with severe sepsis or septic shock due to extended-spectrum B-lactamase-producing Enterobacteriaceae. Int. J. Antimicrob. Agents 2018, 52, 577-585. [CrossRef] [PubMed]

16. Barbier, F.; Pommier, C.; Essaied, W.; Garrouste-Orgeas, M.; Schwebel, C.; Ruckly, S.; Dumenil, A.S.; Lemiale, V.; Mourvillier, B.; Clec'h, C.; et al. Colonization and infection with extended-spectrum 
$\beta$-lactamase-producing Enterobacteriaceae in ICU patients: What impact on outcomes and carbapenem exposure? J. Antimicrob. Chemother. 2016, 71, 1088-1097. [CrossRef]

17. Robineau, O.; Robert, J.; Rabaud, C.; Bedos, J.P.; Varon, E.; Péan, Y.; Gauzit, R.; Alfandari, S. Management and outcome of bloodstream infections: A prospective survey in 121 French hospitals (SPA-BACT Survey). Infect. Drug Resist. 2018, 11, 1359-1368. [CrossRef] [PubMed]

18. Kumar, A.; Zarychanski, R.; Light, B.; Parrillo, J.; Maki, D.; Simon, D.; Laporta, D.; Lapinsky, S.; Ellis, P.; Mirzanejad, Y.; et al. Early combination antibiotic therapy yields improved survival compared with monotherapy in septic shock: A propensity-matched analysis. Crit. Care Med. 2010, 38, 1773-1785. [CrossRef]

19. Leibovici, L.; Vidal, L.; Paul, M. Aminoglycoside drugs in clinical practice: An evidence-based approach. J. Antimicrob. Chemother. 2009, 63, 246-251. [CrossRef] [PubMed]

20. Marcus, R.; Paul, M.; Elphick, H.; Leibovici, L. Clinical implications of $\beta$-lactam-aminoglycoside synergism: Systematic review of randomised trials. Int. J. Antimicrob. Agents 2011, 37, 491-503. [CrossRef]

21. Alfandari, S.; Boussekey, N. Beta-lactams with or without aminoglycosides. Clin. Infect. Dis. 2005, 41, 1542-1543. [CrossRef]

22. Delannoy, P.Y.; Boussekey, N.; Devos, P.; Alfandari, S.; Turbelin, C.; Chiche, A.; Meybeck, A.; Georges, H.; Leroy, O. Impact of combination therapy with aminoglycosides on the outcome of ICU-acquired bacteraemias. Eur. J. Clin. Microbiol. Infect. Dis. 2012, 31, 2293-2299. [CrossRef]

23. Palacios-Baena, Z.R.; Gutierrez-Gutierrez, B.; Calbo, E.; Almirante, B.; Viale, P.; Oliver, A.; Pintado, V.; Gasch, O.; Martinez-Martinez, L.; Pitout, J.; et al. Empiric therapy with carbapenem-sparing regimens for bloodstream infections due to extended-spectrum $\beta$-lactamase-producing enterobacteriaceae: Results from the INCREMENT cohort. Clin. Infect. Dis. 2017, 65, 1615-1623. [CrossRef]

24. Ibrahim, E.H.; Sherman, G.; Ward, S.; Fraser, V.J.; Kollef, M.H. The influence of inadequate antimicrobial treatment of bloodstream infections on patient outcomes in the ICU setting. Chest 2000, 118, 146-155. [CrossRef]

25. Paul, M.; Shani, V.; Muchtar, E.; Kariv, G.; Robenshtok, E.; Leibovici, L. Systematic review and meta-analysis of the efficacy of appropriate empiric antibiotic therapy for sepsis. Antimicrob. Agents Chemother. 2010, 54, 4851-4863. [CrossRef] [PubMed]

26. Adrie, C.; Garrouste-Orgeas, M.; Ibn Essaied, W.; Schewebel, C.; Darmon, M.; Mourvillier, B.; Ruckly, S.; Dumenil, A.S.; Kallel, H.; Argaud, L.; et al. Attributable Mortality of ICU-acquired Bloodstream Infections: Impact of the Source, Causative Micro-Organism, Resistance Profile and Antimicrobial Therapy. J. Infect. 2017, 74, 131-141. [CrossRef]

27. Palacios-Baena, Z.R.; Gutierrez-Gutierrez, B.; De Cueto, M.; Viale, P.; Venditti, M.; Hernandez-Torres, A.; Oliver, A.; Martinez-Martinez, L.; Calbo, E.; Pintado, V.; et al. Development and validation of the INCREMENT-ESBL predictive score for mortality in patients with bloodstream infections due to extended-spectrum-B-lactamase-producing Enterobacteriaceae. J. Antimicrob. Chemother. 2017, 72, 906-913. [CrossRef]

28. Rhodes, A.; Evans, L.E.; Alhazzani, W.; Levy, M.M.; Antonelli, M.; Ferrer, R.; Kumar, A.; Sevransky, J.E.; Sprung, C.L.; Nunnally, M.E.; et al. Surviving sepsis campaign: International guidelines for management of sepsisand septic shock. Intensive Care Med. 2017, 43, 304-377. [CrossRef]

29. Craig, W.A. Optimizing aminoglycosides use. Crit. Care Clin. 2011, 27, 107-121. [CrossRef]

30. Agence Nationale de Sécurité du Médicament et des Produits de Santé. Mise au Point sur le bon Usage des Aminosides Administrés par Voie Injectable: Gentamicine, Tobramycine, Nétilmicine, Amikacine; Agence Nationale de Sécurité du Médicament et des Produits de Santé: Anatole, France, 2011.

31. On Behalf of the Société de Pathologie Infectieuse de Langue Française (SPILF), the Observatoire National de l'Epidémiologie de la Résistance Bactérienne aux Antibiotiques (ONERBA) and the Surveillance de la Prescription des Antibiotiques (SPA) Group; Robert, J.; Péan, Y.; Alfandari, S.; Bru, J.P.; Bedos, J.P.; Rabaud, C.; Gauzit, R. Application of guidelines for aminoglycosides use in French hospitals in 2013-2014. Eur. J. Clin. Microb. Infect. Dis. 2017, 36, 1083-1090. [CrossRef] [PubMed] 
32. Ong, D.S.Y.; Frencken, J.F.; Klein Klouwenberg, P.M.C.; Juffermans, N.; van der Poll, T.; Bonten, M.J.M.; Cremer, O.L.; MARS Consortium. Short-course adjunctive gentamicin as empirical therapy in patients with severe sepsis and septic shock: A prospective observational cohort study. Clin. Infect. Dis. 2017, 64, 1731-1736. [CrossRef]

33. Picard, W.; Bazin, F.; Clouzeau, B.; Bui, H.N.; Soulat, M.; Guilhon, E.; Vargas, F.; Hilbert, G.; Bouchet, S.; Gruson, D.; et al. Propensity based study of aminoglycoside nephrotoxicity in patients with severe sepsis or septic shock. Antimicrob. Agents Chemother. 2014, 58, 7468-7474. [CrossRef] [PubMed]

34. Cobussen, M.; De Kort, J.M.L.; Dennert, R.M.; Lowe, S.H.; Stassen, P.M. No increased risk of acute kidney injury after a single dose of gentamicin in patients with sepsis. Infect. Dis. 2016, 48, 274-280. [CrossRef] [PubMed]

35. Taccone, F.S.; Laterre, P.F.; Spapen, H.; Dugernier, T.; Dellatre, I.; Layeux, B.; De Backer, D.; Wittebole, X.; Wallemacq, P.; Vincent, J.L.; et al. Revisiting the loading dose of amikacin for patients with severe sepsis and septic shock. Crit. Care 2010, 14, R53. [CrossRef]

36. Duszynska, W.; Taccone, F.S.; Hurkacz, M.; Kowalska-Krochmal, B.; Wiela-Hojenska, A.; Kubler, A. Therapeutic drug monitoring of amikacin in septic patients. Crit. Care 2013, 17, R165. [CrossRef] [PubMed]

Publisher's Note: MDPI stays neutral with regard to jurisdictional claims in published maps and institutional affiliations.

(C) 2020 by the authors. Licensee MDPI, Basel, Switzerland. This article is an open access article distributed under the terms and conditions of the Creative Commons Attribution (CC BY) license (http://creativecommons.org/licenses/by/4.0/). 